\title{
Analisis Highest And Best Use Pada Lahan Kosong di Kawasan Perumahan Samudra Residence Brondong Lamongan
}

\author{
Fakhruddin Prasetya Budi ${ }^{1}$ dan I Nyoman Dita Pahang Putra ${ }^{1}$ \\ ${ }^{1}$ Teknik Sipil, Fakultas Teknik, Universitas Pembangunan Nasional Veteran Jawa Timur
}

ARTICLE INFO

Article history

Received : 08 February 2021

Revised : 2 Maret 2021

Accepted : 10 Maret 2021

DOI :

https://doi.org/10.33366/rekabua na.v6i1.2165

Keywords :

highest and best use;

property; vacant land

e-mail corresponding author : fakhruddinbudi@gmail.com

\section{PENERBIT}

UNITRI PRESS

Jl. Telagawarna, TlogomasMalang, 65144, Telp/Fax: 0341-565500

\section{(c) (1) (-)}

This is an open access article under the Creative Commons Attribution-ShareAlike $\quad \mathbf{4 . 0}$ International License. Any further distribution of this work must maintain attribution to the author(s) and the title of the work, journal citation and DOI. CC-BY-SA

\section{ABSTRAK}

Perumahan Samudera Residence merupakan lahan kosong milik PT Sami Karya. Lahan seluas $2.604 \mathrm{~m}^{2}$ itu terdapat pada area utara kabupaten Lamongan kecamatan Brondong, sangat di sayangkan lahan itu masih berbentuk lahan kosong yang belum dipakai, sementara itu lahan tersebut memiliki kesempatan besar untuk dikembangkan menjadi peruntukan yang terbaik. Studi ini bertujuan untuk menganalisa tipe properti apa saja yang bisa di bangun pada lahan kosong itu serta menganalisa tipe properti apa yang bisa memberikan nilai paling tinggi serta terbaik. Tata cara yang dipakai dalam studi ini merupakan Highest and Best Use (HBU). Analisa ini mempunyai 4 standart ialah, secara legal disetujui, secara fisik diperbolehkan, secara finansial menguntungkan, serta bisa meningkatkan produktivitas secara maksimum. Berdasarkan hasil analisa, pilihan properti yang memungkinkan untuk dibentuk merupakan perumahan dan juga pertokoan. Dari pilihan properti tersebut yang memberikan nilai paling tinggi serta terbaik ialah properti pertokoan dengan nilai NPV Rp1.049.892.697, nilai BCR 1,820, nilai IRR 42,01\%, nilai ROI 88,71\%, payback period selama 1 tahun 6 bulan 12 hari, memiliki nilai tanah pasca pengembangan sebesar Rp5.162.064/ $\mathrm{m}^{2}$ dengan produktivitas masksimum sebesar $1.171,75 \%$.

\section{ABSTRACT}

The vacant land in the Samudera Residence Housing area is owned by PT Sami Karya. The $2.604 \mathrm{~m}^{2}$ land is located in the northern area of Lamongan district, Brondong sub-district, it is a pity that the land is still empty land that has not been used, meanwhile this land has a great opportunity to be developed into the best designation. This study aims to analyze what types of properties can be built on that vacant land and to analyze what types of properties provide the highest and best value. The procedure used in this study is Highest and Best Use (HBU). This analysis has 4 standards, namely, legally approved, physically permissible, financially profitable, and can increase productivity to the maximum. Based on the results of the analysis, the possible property options for the establishment are housing and shops. Of the property choices that give the highest and best value are shopping properties with an NPV value of Rp1.049.892.697, BCR value of 1,820, IRR value of 42,01\%, ROI value of $88,71 \%$, payback period of 1 year 6 months 12 days, has a postdevelopment land value of $R p .5 .162 .064 / \mathrm{m}^{2}$ with maximum productivity of $1.171,75 \%$.

Cara Mengutip : Budi, F. P., Putra, I. N. D. P. (2021). Analisis Highest And Best Use pada Lahan Kosong di Kawasan Perumahan Samudra Residence Brondong Lamongan. Reka Buana : Jurnal Ilmiah Teknik Sipil dan Teknik Kimia, 6(1), 1-10. doi:https://doi.org/10.33366/rekabuana.v6i1.2165 


\section{PENDAHULUAN}

Kabupaten Lamongan ialah salah satu kabupaten di Jawa Timur yang bersumber pada struktur keruangan dan masuk dalam pengembangan "Gerbangkertosusila" [1]. Kawasan Gerbangkertosusila merupakan kawasan metropolitan yang berada di provinsi Jawa Timur dengan berbagai kota diantaranya: Gresik, Bangkalan, Mojokerto, Surabaya, Sidoarjo, serta Lamongan, yang menjadikan Surabaya selaku pusat aktivitas ekonominya [2].

Brondong sebagai kota minapolitan atau kota perikanan di Lamongan yang tumbuh dan berkembang karena berjalannya usaha perikanan mampu mendorong dan meningkatkan kegiatan ekonomi daerah sekitarnya yang membawa dampak pada peningkatan mutu kualitas hidup masyarakatnya, sehingga kebutuhan akan penggunaan tanah atau lahan mengalami peningkatan, namun kenyataan yang terjadi di lapangan menampilkan perihal yang sebalikannya, sebab nyatanya masih ada lahan yang dibiarkan kosong ataupun tidak digunakan oleh pemiliknya [3].

Pada penelitian ini, diambil permasalahan tentang lahan kosong yang tidak digunakan dengan memiliki luas sebesar $2.604 \mathrm{~m}^{2}$ dan terletak di kawasan perumahan Samudra Residence Brondong Lamongan dengan memakai analisis Highest and Best Use (HBU).

Analisis highest and best use dapat diartikan sebagai analisis dari penggunaan lahan yang terbaik dan tertinggi karena lahan masih dalam keadaan kosong yang tidak dimanfaatkan ataupun lahan yang sudah terbangun tetapi ingin direncakan ulang [4]. Analisis ini memiliki empat kriteria diantaranya yaitu diijinkan oleh peraturan yang ada (legal premissible), memungkinkan secara fisik (physically possible), layak secara keuangan (financially feasible), dan menghasilkan penghasilan secara maksimum (maximally productive) [5].

Syarat yang pertama yaitu diijinkan dengan cara sah yang sudah diresmikan oleh peraturan pemerintah yang bertujuan supaya lahan objek studi tidak melanggar peraturan pemerintah. Kelayakan pada pandangan ini merujuk pada Rencana Tata Ruang Wilayah (RTRW) serta peraturan-peraturan bangunan (building code) yang berlaku, mencakup GSB, KDB, KLB, KDH, serta tinggi bangunan [6].

Syarat yang kedua yaitu memungkinkan secara fisik, dimana pada pemakaian suatu lahan yang dijadikan sebagai tempat berdirinya sesuatu properti wajib mencermati situasi pada lahan itu, jadi dalam aspek fisik ini ada sebagian standart yang mencakup lokasi lahan, ukuran serta bentuk tanah, aksesibilas ke lokasi serta utilitas [7].

Kelayakan dengan cara finansial dapat dilakukan melalui analisa dengan menggunakan perhitungan aliran kas, yaitu biaya investasi, pendapatan, pengeluaran, NPV (Net Present Value), BCR (Benefit Cost Rasio), IRR (Internal Rate of Return), ROI (Return on Investment), dan payback period [8]. Biaya investasi merupakan anggaran yang dikeluarkan untuk membuat konstruksi dari awal bangun hingga konstruksi berakhir terbuat [9]. Pendapatan merupakan uang yang diperoleh dari perorangan, industri, serta badan lain dalam wujud imbalan, pendapatan, menyewa, bunga, komisi, upah, serta keuntungan [5]. Pengeluaran adalah pengurangan uang yang digunakan untuk pengeluaran listrik, pengeluaran air, pendapatan karyawan, pemeliharaan, keamanan serta penggantian 
berskala [10]. NPV merupakan analisa selisih antara pendapatan serta pengeluaran yang telah dikalikan dengan tingkatan diskonto [11].

$\mathrm{NPV}=-\mathrm{kt}+\frac{\mathrm{b}_{1}-\mathrm{c}_{1}}{(1+\mathrm{i})}+\frac{\mathrm{b}_{2}-\mathrm{c}_{2}}{(1+\mathrm{i})^{2}}+\ldots+\frac{\mathrm{b}_{\mathrm{n}}-\mathrm{c}_{\mathrm{n}}}{(1+\mathrm{i})^{\mathrm{n}}}$

Dimana:

NPV : nilai sekarang bersih

Kt : nilai kapital yang dipakai pada rentang waktu investasi

b1, b2, bn : pendapatan pada tahun ke-1 sampai tahun ke-n

c1, c2, cn : pengeluaran pada tahun ke-1 sampai tahun ke-n

I : tingkat diskonto rate

Apabila NPV > 0, sehingga usulan investasi diterima, sedangkan apabila NPV $<0$, usulan investasi belum dapat diterima dan harus dikaji ulang.

BCR merupakan metode yang menganalisis suatu proyek dengan membandingkan nilai revenue terhadap nilai cost [12].

$\mathrm{BCR}=\frac{\mathrm{B}}{\mathrm{C}}$

Dimana:

$\mathrm{B}=$ nilai dari pendapatan

$\mathrm{C} \quad=$ nilai dari pengeluaran

IRR bertujuan untuk mendapatkan suatu tingkat bunga yang mengibaratkan jumlah yang diharapkan akan diterima dengan jumlah investasi yang harus dikeluarkan [13]. $\operatorname{IRR}=\sum_{\mathrm{t}=0}^{\mathrm{n}} \frac{(\mathrm{c}) \mathrm{t}}{(1+\mathrm{i})^{\mathrm{t}}}-\sum_{\mathrm{t}=0}^{\mathrm{n}} \frac{(\mathrm{C} 0) \mathrm{t}}{(1+\mathrm{i})^{\mathrm{t}}}=0$

Dimana:

IRR : arus pengembalian internal

(c)t : aliran kas masuk tahun ke $\mathrm{n}$

(C0)t : aliran kas keluar tahun ke $\mathrm{n}$

n : periode investasi

i : tingkat diskonto rate

t : tahun

Jika IRR > discount factor, sehingga usulan diterima, sedangkan jika IRR $<$ discount factor, sehingga usulan ditolak.

ROI ialah salah satu bagian dari perbandingan profitabilitas yang selalu dipakai dalam memperhitungkan sesuatu kemampuan finansial perusahaan berdasarkan laporan keuangan dan profit perusahaan [14].

ROI $=\frac{\text { Net profit }}{\text { Total Assets }} \times 100 \%$

Apabila ROI > discount factor, maka usulan diterima, sedangkan apabila ROI < discount factor, maka usulan ditolak. 
PP merupakan suatu metode penilaian pada periode durasi ataupun periode khusus yang dipakai untuk menutup initial investment dari sesuatu proyek [15].

$\mathrm{x}=\mathrm{d}+\left\{\left(\frac{\mathrm{b}-\mathrm{a}}{\mathrm{c}-\mathrm{a}}\right) \times(\mathrm{e}-\mathrm{d})\right\}$

Dari kegunaan yang telah lulus dalam aspek legal, aspek fisik serta aspek finansial dapat dilanjutkan dengan mencari nilai dari suatu lahan dengan cara menganalisa produktivitas maksimumnya, maka kegunaan yang menghasilkan produktivitas yang maksimal atau memiliki nilai tertinggi merupakan hasil akhir dari kegunaan tertinggi dan terbaik [16].

\section{METODE PENELITIAN}

Penelitian ini memakai teori Highest and Best Use untuk menganalisis penggunaan lahan kosong yang bisa menciptakan tipe properti paling tinggi serta terbaik. Pada penelititian ini hal yang dilakukan pertama yaitu pengumpulan data. Pada pengumpulan data ini terdapat 2 jenis data yaitu data primer serta data sekunder, setelah melakukan pengumpulan data dapat dilanjutkan dengan melakukan pemilihan alternatif bangunan dengan cara observasi lapangan dan juga pembagian kuisioner, pada tahap ini digunakan untuk memilih properti yang diinginkan oleh stake holder terkait yang selanjutnya di analisis dengan menggunakan metode highest and best use yang terdiri dari aspek legal, aspek fisik, aspek finansial, dan produktivitas maksimum. Pada penelitian ini memiliki daya tarik tersendiri, dimana pada aspek finansial membahas lebih detail lagi dibandingkan dengan penelitian sebelumnya. Rincian variabel penelitian data bisa diamati pada Tabel 1.

Tabel 1. Variabel Penelitian

\begin{tabular}{|c|c|c|c|c|c|}
\hline Topik & $\begin{array}{c}\text { Variabel } \\
\text { Penelelitian } \\
\end{array}$ & Klasifikasi & $\begin{array}{c}\text { Data yang } \\
\text { dibutuhkan }\end{array}$ & Tipe Data & $\begin{array}{c}\text { Sumber } \\
\text { Data }\end{array}$ \\
\hline $\begin{array}{l}\text { Pemilihan } \\
\text { alternatif }\end{array}$ & $\begin{array}{c}\text { Alternatif } \\
\text { penggunaan }\end{array}$ & $\begin{array}{c}\text { Penentuan alternatif } \\
\text { penggunaan }\end{array}$ & $\begin{array}{l}\text { Data subyek } \\
\text { dan data fisik }\end{array}$ & Primer & $\begin{array}{c}\text { Observasi } \\
\text { Lapangan } \\
\text { dan kuisioner }\end{array}$ \\
\hline $\begin{array}{l}\text { Analisa } \\
\text { penggunaan } \\
\text { tertinggi dan } \\
\text { terbaik }\end{array}$ & Aspek legal & $\begin{array}{l}\text { a. Zoning } \\
\text { b. Building code }\end{array}$ & $\begin{array}{l}\text { 1. RTRWk } \\
\text { 2. GSB, } \\
\text { KDB, KLB, } \\
\text { KDH, dan } \\
\text { ketinggian } \\
\text { bangunan }\end{array}$ & Sekunder & $\begin{array}{l}\text { Dinas Cipta } \\
\text { Karya dan } \\
\text { Tata Ruang } \\
\text { Kota } \\
\text { Lamongan }\end{array}$ \\
\hline $\begin{array}{c}\text { Analisa } \\
\text { penggunaan } \\
\text { tertinggi dan } \\
\text { terbaik }\end{array}$ & Aspek fisik & $\begin{array}{l}\text { a. Lokasi Lahan } \\
\text { b. Bentuk dan Ukuran tanah } \\
\text { c. Utilitas } \\
\text { d. aksesibilatas }\end{array}$ & $\begin{array}{l}\text { Layout } \\
\text { eksisting } \\
\text { lahan }\end{array}$ & $\begin{array}{l}\text { Primer } \\
\text { dan } \\
\text { Sekunder }\end{array}$ & $\begin{array}{l}\text { Observasi } \\
\text { Lapangan } \\
\text { dan } \\
\text { wawancara }\end{array}$ \\
\hline
\end{tabular}




\begin{tabular}{|c|c|c|c|c|c|}
\hline $\begin{array}{c}\text { Analisa } \\
\text { penggunaan } \\
\text { tertinggi dan } \\
\text { terbaik }\end{array}$ & $\begin{array}{l}\text { Aspek } \\
\text { finansial }\end{array}$ & $\begin{array}{l}\text { a. Biaya Investasi } \\
\text { b. Pendapatan } \\
\text { c. Pengeluaran } \\
\text { d. Aliran Kas } \\
\text { e. Net Present Value (NPV) } \\
\text { f. Benefit Cost Rasio (BCR) } \\
\text { g. Internal Rate of Return } \\
\text { (IRR) } \\
\text { h. Return on Investment } \\
\text { (ROI) } \\
\text { i. Payback Period }\end{array}$ & $\begin{array}{l}\text { Harga tanah } \\
\text { objek } \\
\text { penelitian dan } \\
\text { harga satuan } \\
\text { biaya }\end{array}$ & Sekunder & $\begin{array}{c}\text { Data-data } \\
\text { pendekatan } \\
\text { properti } \\
\text { sejenis }\end{array}$ \\
\hline $\begin{array}{c}\text { Analisa } \\
\text { penggunaan } \\
\text { tertinggi dan } \\
\text { terbaik }\end{array}$ & $\begin{array}{l}\text { Produktivitas } \\
\text { maksimum }\end{array}$ & Nilai lahan & Nilai Properti & Primer & $\begin{array}{c}\text { Perhitungan } \\
\text { hasil dari } \\
\text { analisa aspek } \\
\text { finansial }\end{array}$ \\
\hline
\end{tabular}

Sumber: Hasil Olahan Penulis

\section{HASIL DAN PEMBAHASAN}

\subsection{Penetapan Alternatif Penggunaan}

Bersumber pada hasil penyebaran kuisioner pada pemilik lahan dan warga sekitar, sehingga diperoleh pilihan properti berupa perumahan rumah menengah serta pertokoan.

\subsection{Aspek Legal}

Peraturan RTRW untuk alternatif perumahan yang di peruntukan pada Jalan Desa di kawasan perumahan Samudra Residence Brondong adalah sebagai berikut:

1) GSB memiliki ketentuan:

- Bangunan di jalan kolektor primer minimal 4,5 meter

- Bangunan di jalan local sekunder minimal 4 meter

- Bangunan di jalan lingkungan minimal 3,5 meter

2) KDB maksimal $65 \%$

3) KLB maksimal 1,3

4) $\mathrm{KDH}$ minimal $10 \%$

5) Ketinggian bangunan 3-4 meter

6) Rata-rata jumlah lantai: 1 lantai

Peraturan RTRW untuk alternatif pertokoan yang di peruntukan pada Jalan Desa di kawasan perumahan Samudra Residence Brondong adalah sebagai berikut:

1) GSB memiliki ketentuan:

- Bangunan di jalan kolektor primer minimal 4,5 meter

- Bangunan di jalan local sekunder minimal 4 meter

- Bangunan di jalan lingkungan minimal 3,5 meter

2) KDB maksimal $60 \%$

3) KLB maksimal 1-1,8

4) $\mathrm{KDH}$ minimal $10 \%$

5) Ketinggian bangunan 3-4 meter

6) Rata-rata jumlah lantai: 1-2 lantai 


\subsection{Aspek Fisik}

Dalam analisa aspek fisik terdapat sebagian standart yang mencakup lokasi lahan, bentuk serta ukuran tanah, utilitas, dan aksesibilitas.

1) Lokasi Lahan

Bersumber pada data yang ada, lahan kosong ini berada di kawasan perumahan Samudra Residence Kecamatan Brondong, Kabupaten Lamongan. Lahan penelitian sesuai untuk dikembangkan sebagai properti komersial sebab terdapat di area perumahan serta bersebelahan dengan area perikanan ataupun pasar.

2) Ukuran dan Bentuk Lahan

Berdasarkan data ukuran lahan yang ada, lahan memiliki luas sebesar $2.604 \mathrm{~m}^{2}$. Bentuk dari lahan ini kurang beraturan dan juga memiliki kontur tanah yang tidak merata.

3) Utilitas

Berdasarkan observasi di lapangan, dapat dilihat untuk segi utilitas ataupun sarana umum, lahan ini memiliki kelengkapatan fasilitas umum yang sangat menunjang. Disekitar lahan ini sudah dilengkapi dengan sarana penunjang utama seperti air, listrik, dan sarana komunikasi.

4) aksesibilitas

Berdasarkan data hasil observasi, aksesibilatas lahan pada objek penelitian ini dapat di akses melalui dua jalan dan juga lahan ini dapat dijangkau dengan alat transprotasi pribadi seperti mobil ataupun sepeda motor.

\subsection{Aspek Finansial}

Langkah berikutnya sesudah menganalisa aspek legal serta aspek fisik adalah aspek finansial. Analisa aspek finansial mencakup biaya investasi, pendapatan, pengeluaran, dan analisa kelayakan berdasarkan lima indikator diantaranya Net Present Value (NPV), Benefit Cost Rasio (BCR), Internal Rate Return (IRR), Return On Invesment (ROI), dan Payback Period (PP).

\section{1) Biaya Investasi}

Biaya investasi pada penelitian ini diasumsikan selama 2 tahun. Berdasarkan perhitungan tersebut, biaya investasi pada setiap alternatif properti dapat dilihat pada Tabel 2.

Tabel 2. Biaya Investasi

\begin{tabular}{lr}
\hline \multicolumn{1}{c}{ Jenis Alternatif } & Biaya Investasi (Rp) \\
\hline Rumah Menengah & 3.751 .273 .800 \\
Pertokoan & 4.025 .151 .000 \\
\hline
\end{tabular}

Sumber: Hasil Olahan Penulis

\section{2) Perencanaan Pendapatan}

Perencanaan pendapatan untuk semua pilihan properti berasal dari penjualan serta service charge. Besar nilai pendapatan dapat dilihat pada Tabel 3. 
Tabel 3. Pendapatan

\begin{tabular}{ccc}
\hline Tahun & Perumahan & Pertokoan \\
\hline 1 & Rp2.669.529.467 & Rp3.266.627.988 \\
2 & Rp2.682.129.467 & Rp3.008.427.503 \\
\hline \multicolumn{4}{c}{ Sumber: Hasil Olahan Penulis }
\end{tabular}

\section{3) Perencanaan Pengeluaran}

Perencanaan pengeluaran untuk semua pilihan properti berasal dari biaya operasional yang mencakup gaji, listrik, dan air, biaya pemeliharaan, ijin serta IMB, uruk dan pemadatan, fasum sarana prasarana, pajak, dan yang terakhir notaris. Besar nilai pengeluaran dapat dilihat pada Tabel 4.

Tabel 4. Pengeluaran

\begin{tabular}{ccc}
\hline Tahun & Perumahan & Pertokoan \\
\hline 1 & Rp263.055.397 & Rp311.121.890 \\
2 & Rp249.517.397 & Rp288.835.890 \\
\hline \multicolumn{4}{c}{ Sumber: Hasil Olahan Penulis }
\end{tabular}

\section{4) Analisa Kelayakan}

Analisa kelayakan dilakukan dengan menggunakan lima indikator diantaranya yaitu Net Present Value (NPV), Benefit Cost Rasio (BCR), Internal Rate Return (IRR), Return On Invesment (ROI), dan Payback Period (PP). Pada Analisa kelayakan ini menggunakan suku bunga yang diperoleh dari rata-rata beberapa suku bunga dasar kredit yang ada di Indonesia. Nilai suku bunga setiap bank dapat dilihat pada Tabel 5.

Tabel 5. Suku Bunga Dasar Kredit Non KPR

\begin{tabular}{lr}
\hline \multicolumn{1}{c}{ Bank } & Suku Bunga (\%) \\
\hline BRI & 12,00 \\
BCA & 8,61 \\
BNI & 11,95 \\
MANDIRI & 11,90 \\
CIMB NIAGA & 9,95 \\
Rata-rata & $\mathbf{1 0 , 8 0}$ \\
\hline \multicolumn{2}{c}{ Sumber: www.ojk.go.id }
\end{tabular}

Berdasarkan nilai suku bunga tersebut dapat dilanjutkan untuk melakukan perhitungan pada analisa kelayakan, yaitu:

Net Present Value (NPV)

Analisa perhitungan NPV untuk rumah menengah dapat dilihat pada Tabel 6.

Tabel 6. Analisa NPV Perumahan

\begin{tabular}{ccccc}
\hline & & \multicolumn{3}{c}{ Tahun } \\
\cline { 3 - 5 } No & Uraian & $\mathbf{2 0 1 9}$ & $\mathbf{2 0 2 0}$ & $\mathbf{2 0 2 1}$ \\
\cline { 3 - 5 } & & $\mathbf{0}$ & $\mathbf{1}$ & $\mathbf{2}$ \\
\hline 1 & MARR & $10,88 \%$ & & \\
2 & Investasi & $(1.875 .636 .900)$ & $(1.875 .636 .900)$ & 2.682 .129 .467
\end{tabular}




\begin{tabular}{rcccc}
4 & Pengeluaran & & $(263.055 .397)$ & $(249.517 .397)$ \\
5 & Net Cash Flow & $(1.875 .636 .900)$ & 530.837 .169 & 2.432 .612 .069 \\
6 & Discount Factor & 1,0000000 & 0,9018759 & 0,8133801 \\
7 & Discounted Cash & $(1.875 .636 .900)$ & 478.749 .251 & 1.978 .638 .351 \\
& Flow & $\mathbf{5 8 1 . 7 5 0 . 7 0 2}$ & & \\
8 & NPV & & \\
\hline
\end{tabular}

Sumber: Hasil Olahan Penulis

Analisa perhitungan NPV untuk pertokoan dapat dilihat pada Tabel 7.

Tabel 7. Analisa NPV Pertokoan

\begin{tabular}{|c|c|c|c|c|}
\hline No & Uraian & $\begin{array}{c}2019 \\
0\end{array}$ & $\begin{array}{c}\text { Tahun } \\
2020 \\
1\end{array}$ & $\begin{array}{c}2021 \\
2\end{array}$ \\
\hline 1 & MARR & $10,88 \%$ & & \\
\hline 2 & Investasi & $(2.012 .575 .500)$ & $(2.012 .575 .500)$ & \\
\hline 3 & Pendapatan & & 3.266.627.988 & 3.088 .427 .503 \\
\hline 4 & Pengeluaran & & $(311.121 .890)$ & $(288.835 .890)$ \\
\hline 5 & Net Cash Flow & $(2.012 .575 .500)$ & 942.930 .598 & 2.719 .591 .613 \\
\hline 6 & Discount Factor & 1,0000000 & 0,9018759 & 0,8133801 \\
\hline 7 & $\begin{array}{l}\text { Discounted Cash } \\
\text { Flow }\end{array}$ & $(2.012 .575 .500)$ & 850.406 .384 & 2.212 .061 .813 \\
\hline 8 & NPV & 1.049.892.697 & & \\
\hline
\end{tabular}

Sumber: Hasil Olahan Penulis

Benefit Cost Rasio (BCR)

Analisa perhitungan BCR untuk properti rumah menengah dan pertokoan dapat dilihat pada Tabel 8.

Tabel 8. Analisa Perhitungan BCR

\begin{tabular}{crr}
\hline \multirow{2}{*}{ Uraian } & \multicolumn{2}{c}{ Alternatif Properti } \\
& Perumahan & \multicolumn{1}{c}{ Pertokoan } \\
\hline $\begin{array}{c}\text { Investasi } \\
\text { Cash }\end{array}$ & $\begin{array}{r}(1.875 .636 .900) \\
(2.012 .575 .500) \\
\text { Flow } \\
\text { tahun I } \\
\text { Cash }\end{array}$ & 942.930 .598 \\
Flow & 2.432 .612 .069 & 2.719 .591 .613 \\
tahun II \\
BCR
\end{tabular}

Internal Rate Return (IRR)

Analisa perhitungan IRR untuk properti rumah menengah dan pertokoan dapat dilihat pada Tabel 9.

Tabel 9. Analisa Perhitungan IRR

\begin{tabular}{lrr}
\hline \multirow{2}{*}{ Uraian } & \multicolumn{2}{c}{ Alternatif Properti } \\
& Perumahan & \multicolumn{1}{c}{ Pertokoan } \\
\hline Investasi & $(1.875 .636 .900)$ & $(2.012 .575 .500)$ \\
Cash & 530.837 .169 & 942.930 .598 \\
Flow & & \\
tahun I & &
\end{tabular}




\begin{tabular}{lcr} 
Cash & 2.432 .612 .069 & 2.719 .591 .613 \\
$\begin{array}{l}\text { Flow } \\
\text { tahun II }\end{array}$ & & \\
IRR & $\mathbf{2 8 , 9 1 \%}$ & $\mathbf{4 2 , 0 1 \%}$ \\
\hline \multicolumn{3}{c}{ Sumber: Hasil Olahan Penulis }
\end{tabular}

Return On Invesment (ROI)

Analisa perhitungan ROI untuk properti rumah menengah dan pertokoan dapat dilihat pada Tabel 10.

Tabel 10. Analisa Perhitungan ROI

\begin{tabular}{|c|c|c|}
\hline \multirow{2}{*}{ Uraian } & \multicolumn{2}{|c|}{ Alternatif Properti } \\
\hline & Perumahan & Pertokoan \\
\hline Investasi & $(1.875 .636 .900)$ & $(2.012 .575 .500)$ \\
\hline Cash & 530.837 .169 & 942.930 .598 \\
\hline $\begin{array}{l}\text { Flow } \\
\text { tahun I }\end{array}$ & & \\
\hline Cash & 2.432.612.069 & 2.719 .591 .613 \\
\hline Flow & & \\
\hline tahun II & & \\
\hline $\begin{array}{c}\text { Annual } \\
\text { NOI }\end{array}$ & 1.432 .665 .176 & 1.785 .429 .183 \\
\hline ROI & $76,38 \%$ & $88,71 \%$ \\
\hline
\end{tabular}

Payback Period (PP)

Analisa perhitungan PP untuk properti rumah menengah dan pertokoan dapat dilihat pada Tabel 11.

Tabel 11. Analisa Perhitungan PP

\begin{tabular}{|c|c|c|}
\hline \multirow{2}{*}{ Uraian } & \multicolumn{2}{|c|}{ Alternatif Properti } \\
\hline & Perumahan & Pertokoan \\
\hline Investasi & $(1.875 .636 .900)$ & $(2.012 .575 .500)$ \\
\hline Cash & 530.837 .169 & 942.930 .598 \\
\hline \multicolumn{3}{|l|}{ Flow } \\
\hline \multicolumn{3}{|l|}{ tahun I } \\
\hline Cash & 2.432.612.069 & 2.719.591.613 \\
\hline \multicolumn{3}{|l|}{ Flow } \\
\hline \multicolumn{3}{|l|}{ tahun II } \\
\hline PP & 1,650 & 1,532 \\
\hline
\end{tabular}

Berdasarkan perhitungan diatas, rekapitulasi perhitungan analisa kelayakan dapat dilihat pada Tabel 12.

Tabel 12. Rekapitulasi Analisa Kelayakan

\begin{tabular}{lrr}
\hline \multirow{2}{*}{ Uraian } & \multicolumn{2}{c}{ Alternatif Properti } \\
& \multicolumn{1}{c}{ Perumahan } & \multicolumn{1}{c}{ Pertokoan } \\
\hline NPV & Rp581.750.702 & Rp1.049.892.697 \\
BCR & 1,580 & 1,820 \\
IRR & $28,91 \%$ & $42,01 \%$ \\
ROI & $76,38 \%$ & $88,71 \%$ \\
PP & 1,650 tahun & 1,532 tahun \\
\hline \multicolumn{3}{c}{ Sumber: Hasil Olahan Penulis }
\end{tabular}




\subsection{Produktivitas Maksimum}

Pada analisa kali ini bermaksud untuk mendapatkan nilai lahan tertinggi dari masingmasing properti yang dilakukan selama 2 tahun. Hasil perhitungan produktivitas maksimum dapat dilihat pada Tabel 13.

Tabel 13. Produktivitas maksimum

\begin{tabular}{clrr}
\hline \multirow{2}{*}{ No. } & \multicolumn{1}{c}{ Uraian } & Aerumahan & \multicolumn{1}{c}{ Pertokoan } \\
\hline 1 & Aset Properti & 13.167 .878 .453 & 16.410 .194 .693 \\
2 & Biaya Investasi & $(3.751 .273 .800)$ & $(4.025 .151 .000)$ \\
3 & Biaya Tanah & 1.056 .971 .000 & 1.056 .971 .000 \\
4 & Nilai Bangunan & 2.694 .302 .800 & 2.968 .180 .000 \\
5 & Nilai Tanah & 10.473 .575 .653 & 13.442 .014 .693 \\
6 & Nilai Tanah Pasca & 4.022 .110 & 5.162 .064 \\
& Pengembangan/m ${ }^{2}$ & & 405.903 \\
7 & Nilai Tanah Awal $/ \mathrm{m}^{2}$ & 405.903 & $1171,75 \%$ \\
8 & Produktivitas Tanah & $890,90 \%$ & \\
\hline
\end{tabular}

Sumber: Hasil Olahan Penulis

Berdasarkan Tabel 13, nilai tanah tertinggi didapat dari properti pertokoan yakni sebesar Rp5.162.064/m² dengan produktivitas tertinggi sebesar $1.171,75 \%$ pada tahun kedua.

\section{KESIMPULAN}

Berdasarkan analisa Highest and Best Use yang telah dilakukan, properti yang dapat memberikan nilai lahan tertinggi dan terbaik yaitu properti pertokoan dengan memiliki nilai NPV Rp1.049.892.697, nilai BCR 1,820, nilai IRR 42,01\%, nilai ROI $88,71 \%$, payback period selama 1 tahun 6 bulan 12 hari, memiliki nilai tanah pasca pengembangan sebesar Rp5.162.064/ $\mathrm{m}^{2}$ dengan produktivitas masksimum sebesar $1.171,75 \%$ pada tahun kedua, jadi dapat disimpulkan bahwa peruntukan lahan untuk perkembangan properti pertokoan adalah alternatif penggunaan terbaik.

\section{DAFTAR PUSTAKA}

[1] Kementerian Pekerjaan Umum dan Perumahan Rakyat. (2013). Penyusunan Rencana Detail Tata Ruang Kawasan (RDTK) Kecamatan Brondong Kabupaten Lamongan Tahun 2013-2033. pp. 1-8.

[2] Putri, N. A dan Soelistyo, A. (2018). "Analisis Pengaruh Upah, PDRB, dan Investasi terhadap Penyebaran Tenaga Kerja di Kawasan Gerbangkertasusila Tahun 2012-2016," Jurnal Ilmu Ekonomi., vol. 2, pp. 357-371.

[3] Istiana dan Deswati, R. H. (2014). "Persepsi Pembudidaya terhadap Pengenalan Teknologi Pembuatan Pakan Ikan Berbahan Baku Lokal di Kecamatan Paciran, 
Kabupaten Lamongan,” in Seminar Nasional Kelautan IX, vol. 1, no. 1, pp. 22-25.

[4] Putra, I. N. D. P., Anwar, N., and Utomo, C. (2013). "The Concept and Development of Land Value Assessment," Int. Conf. Inf. Syst. Bus. Compet., pp. 301-306.

[5] Anggarawati, B dan Utomo, C. (2013). "Analisa Penggunaan Lahan Kawasan Komersial Perumahan Citra Raya Surabaya dengan Metode Highest and Best Use," Jurnal Teknik Pomits, vol. 2, no. 2, pp. 39-41.

[6] Rasyid, T. D. A dan Utomo, C. (2013). "Analisa Highest And Best Use (HBU) pada Lahan Bekas SPBU Biliton Surabaya," Jurnal Teknik Pomits, vol. 2, no. 2.

[7] Herradiyanti, M., Utomo, C., dan Putri, Y. E. (2016). “Analisa Penggunaan Tertinggi dan Terbaik (Highest and Best Use Analysis) pada Lahan Pasar Turi Lama Surabaya," Jurnal Teknik ITS, vol. 5, no. 2, pp. 172-175.

[8] Faradiany, F. V. dan Utomo, C. (2014). “Analisa Highest and Best Use Pada Lahan Kosong Di Jemur Gayungan II Surabaya," Jurnal Teknik Pomits, vol. 3, no. 2, pp. $61-63$.

[9] Utami, N. P. K and Utomo, C. (2015). "Analisa Highest and Best Use Pada Lahan Kosong Di Kawasan Wisata Ubud,” Jurnal Teknik ITS, vol. 4, no. 1, pp. C41-C44.

[10] Azinuddin, M. R dan Indryani, R. (2014). "Analisa Highest and Best Use Pada Lahan Kosong Nomor 52-58 Di Jalan Dinoyo Surabaya," Jurnal Teknik ITS, vol. 4, no. 2 , pp. 56-58.

[11] Nufaili, R dan Utomo, C. (2014). "Analisa Investasi Hotel Pesonna Makassar," Jurnal Teknik Pomits, vol. 3, no. 2, pp. D143-D146.

[12] Adi, A. P., Handayani, F. S., and Setiono. (2016). "Analisis Kelayakan Investasi dan Optimalisasi Komposisi Jumlah Tipe Rumah untuk Mendapatkan Keuntungkan Optimum pada Perumnas Jeruk Sawit Permai Karanganyar," e-Jurnal MATRIKS Teknik Sipil, pp. 1238-1243.

[13] Prastiwi, A dan Utomo, C. (2013). "Analisa Investasi Perumahan Green Semanggi Mangrove Surabaya," Jurnal Teknik Pomits, vol. 2, no. 2, pp. D191-D196.

[14] Romadhani, A., Endang, M. G. W., dan Sulasmiyati, S. (2016). “Analisis Return On Invesment (ROI) dan Residual Income (RI) Untuk Menilai Kerja Keuangan Perusahaan,” Jurnal Administrasi Bisnis, vol. 37, no. 1, pp. 1-8.

[15] Yasuha, J dan Saifi, M. (2017). "Analisis kelayakan Investasi Atas Rencana Penambahan Aktiva Tetap," Jurnal Administrasi Bisnis, vol. 46, no. 1, pp. 113-121.

[16] Azis, C. N dan Utomo, C. (2015). "Analisa Highest and Best Use pada Lahan Gedung Serbaguna Purnama," J. Tek. ITS, vol. 4, no. 1, pp. D51-D53. 